\title{
Hyperbaric oxygen treatment in autism spectrum disorders
}

Daniel A Rossignol ${ }^{1 *}$, James J Bradstreet ${ }^{2,3}$, Kyle Van Dyke ${ }^{4}$, Cindy Schneider ${ }^{5}$, Stuart H Freedenfeld ${ }^{6}$, Nancy O'Hara ${ }^{7}$, Stephanie Cave ${ }^{8}$, Julie A Buckley ${ }^{9}$, Elizabeth A Mumper ${ }^{10}$ and Richard E Frye ${ }^{11}$

\begin{abstract}
Traditionally, hyperbaric oxygen treatment (HBOT) is indicated in several clinical disorders include decompression sickness, healing of problem wounds and arterial gas embolism. However, some investigators have used HBOT to treat individuals with autism spectrum disorders (ASD). A number of individuals with ASD possess certain physiological abnormalities that HBOT might ameliorate, including cerebral hypoperfusion, inflammation, mitochondrial dysfunction and oxidative stress. Studies of children with ASD have found positive changes in physiology and/or behavior from HBOT. For example, several studies have reported that HBOT improved cerebral perfusion, decreased markers of inflammation and did not worsen oxidative stress markers in children with ASD. Most studies of HBOT in children with ASD examined changes in behaviors and reported improvements in several behavioral domains although many of these studies were not controlled. Although the two trials employing a control group reported conflicting results, a recent systematic review noted several important distinctions between these trials. In the reviewed studies, HBOT had minimal adverse effects and was well tolerated. Studies which used a higher frequency of HBOT sessions (e.g., 10 sessions per week as opposed to 5 sessions per week) generally reported more significant improvements. Many of the studies had limitations which may have contributed to inconsistent findings across studies, including the use of many different standardized and non-standardized instruments, making it difficult to directly compare the results of studies or to know if there are specific areas of behavior in which HBOT is most effective. The variability in results between studies could also have been due to certain subgroups of children with ASD responding differently to HBOT. Most of the reviewed studies relied on changes in behavioral measurements, which may lag behind physiological changes. Additional studies enrolling children with ASD who have certain physiological abnormalities (such as inflammation, cerebral hypoperfusion, and mitochondrial dysfunction) and which measure changes in these physiological parameters would be helpful in further defining the effects of HBOT in ASD.
\end{abstract}

Keywords: Hyperbaric oxygen treatment, Autism, Oxidative stress, Inflammation, Behavior

\section{Introduction}

Hyperbaric oxygen treatment (HBOT) involves inhaling up to $100 \%$ oxygen at a pressure greater than one atmosphere (atm) in a pressurized chamber [1]. HBOT is indicated in several clinical disorders include decompression sickness, healing of problem wounds, arterial gas embolism and carbon monoxide poisoning [2]. Treatment with HBOT for these disorders uses higher pressures (over $2.0 \mathrm{~atm}$ ). Higher pressure HBOT has

\footnotetext{
* Correspondence: rossignolmd@gmail.com

${ }^{1}$ Rossignol Medical Center, 3800 West Eau Gallie Blvd., Melbourne, FL 32934, USA

Full list of author information is available at the end of the article
}

been shown to increase the oxygen content of plasma [3] and body tissues [4] and may normalize oxygen levels in ischemic tissues [5].

As compared to treatment with HBOT for many classical indications, HBOT used at lower pressures (e.g. 1.3 to $1.5 \mathrm{~atm}$ and oxygen at 24 to $100 \%$ ) has started to be investigated to treat certain neurological disorders, some of which are considered to have few efficacious treatments. For example, recent studies have investigated lower pressure $\mathrm{HBOT}$ for traumatic brain injury (TBI) in both animal models [6-10] and humans [11-23]. In a recent prospective trial of 16 patients with TBI, HBOT at $1.5 \mathrm{~atm} / 100 \%$ oxygen ( 40 hourly treatments over 30 days)
C Biomed Central 
resulted in significant improvements in their neurological exam, IQ, memory, post-traumatic stress symptoms, depression, anxiety and quality of life. Patients also displayed objective improvements in brain perfusion measured by pre- and post-HBOT single photon emission computed tomography (SPECT) scans [17]. The human studies of TBI also include a controlled retrospective review and a controlled prospective clinical trial $[15,18]$. Larger multicenter trials are ongoing in attempt to confirm these controlled clinical studies [24].

Other neurological disorders have been reported to improve with lower pressure HBOT; one investigator reported significant improvements in IQ for a 15 year old child who had fetal alcohol syndrome using HBOT at $1.5 \mathrm{~atm} / 100 \%$ oxygen for 73 sessions [25]. Some investigators have reported that HBOT possesses neuroprotective effects $[8,26,27]$. Interestingly, oxygen supplementation has recently been reported to enhance cognition [17]. For example, in several double-blind studies of healthy young adults, the use of supplementary oxygen, when compared with room air, significantly enhanced memory [28], cognitive performance, word recall and reaction time for 24 hours [29], as well as attention and picture recognition [30].

Autism spectrum disorders (ASD) are a heterogeneous group of neurodevelopmental disorders that are defined by behavioral observations and are characterized by impairments in communication and social interaction along with restrictive and repetitive behaviors [31]. ASD includes autistic disorder, Asperger syndrome, and pervasive developmental disorder-not otherwise specified (PDD-NOS). An estimated 1 out of 110 individuals in the United States is currently affected with an ASD [32]. The etiology of ASD is unclear at this time. Although several genetic syndromes, such as Fragile $\mathrm{X}$ and Rett syndromes, have been associated with ASD, empirical studies have estimated that genetic syndromes only account for $6-15 \%$ of ASD cases [33]. Therefore, the majority of ASD cases are not due to a simple single gene or chromosomal disorder. Although many of the cognitive and behavioral features of ASD are thought to arise from dysfunction of the central nervous system (CNS), evidence from many fields of medicine has documented multiple non-CNS physiological abnormalities associated with ASD [34-37], suggesting that, in some individuals, ASD arises from systemic, rather than organ specific, abnormalities. Specifically, in recent decades, research and clinical studies in ASD have implicated physiological and metabolic systems that transcend specific organ dysfunction, such as cerebral hypoperfusion, immune dysregulation, inflammation, oxidative stress, and mitochondrial dysfunction [38,39]. In this context, ASD may arise from, or at least involve, systemic physiological abnormalities rather than being a purely CNS disorder, at least in a subset of individuals with ASD [40].
To date, ASD has few efficacious treatments. Applied Behavioral Analysis (ABA) is a form of behavioral therapy which has been reported to lead to improvements in some children with ASD. ABA treats the behavioral manifestations of ASD. Studies of ABA generally observe children with ASD over a period of one to two years. Lovaas first reported that ABA resulted in significant gains in IQ and behavioral problems over a 2 year period of time in some children with ASD [41]. Researchers from the Wisconsin Early Autism Project observed similar behavioral and IQ improvements with ABA after 4 years of observations [42]. However, only modest gains were detected using ABA compared to eclectic therapy by researchers in Norway when children were observed for only one year [43]. Therefore, behavioral therapies typically require long time periods to cause behavioral and cognitive changes in children with ASD.

Some treatments for ASD target physiological abnormalities that have been reported in some children. However, very few of these types of treatments have been critically evaluated. Starting around 2005, some investigators speculated that HBOT may be useful in improving behavioral and physiological abnormalities found in some children with ASD [44-48]. This manuscript will review the current evidence for HBOT as a treatment for ASD. First, the effects of HBOT on physiological abnormalities in children with ASD will be reviewed. Secondly, the effects on autistic behaviors will be discussed. Finally, potential adverse effects of HBOT in ASD and limitations of studies will be reviewed.

\section{The effects of HBOT on physiological abnormalities in ASD}

\section{Cerebral hypoperfusion in ASD and the effects of HBOT}

A number of studies have reported cerebral hypoperfusion in individuals with ASD compared to controls as measured by positron emission tomography (PET), SPECT or functional magnetic resonance imaging (fMRI) [49-51]. This hypoperfusion has been correlated with certain autistic behaviors such as repetitive behaviors [52], desire for sameness [53], impairments in processing facial expressions and emotions [54], and decreased language development [55]. Furthermore, lower cerebral perfusion has been significantly correlated with increasing age in children with ASD [55] and with more severe autistic behaviors [56].

It is possible that HBOT could improve cerebral perfusion in ASD. Several studies have reported significant improvements in cerebral perfusion with the use of HBOT at lower pressures (i.e., 1.3 to $1.5 \mathrm{~atm}$ ), as measured by pre- and postHBOT SPECT scans in several neurological conditions, including TBI and chronic brain injury $[16,17,19,22]$. In addition, cerebral perfusion has been shown to change in children with ASD after treatment with HBOT. For example, several case reports have demonstrated improvements in 
cerebral perfusion, as measured by pre- and post-treatment SPECT scans, with the use of HBOT at $1.3 \mathrm{~atm} / 24 \%$ oxygen, including one child with ASD who received 1 hour of HBOT per day for 10 consecutive days [57] and two children with ASD who received 40-80 treatments [58]. Behavioral improvements were observed in these children as well. Figure 1a-b demonstrates the pre- and post-HBOT SPECT scans in one child from this latter case report [58].

Kinaci et al. reported on the cerebral perfusion effects of $\mathrm{HBOT}$ at $1.5 \mathrm{~atm} / 100 \%$ oxygen for 50 sessions at 60 minutes per day in 108 children with ASD [59]. At baseline, all 108 patients had normal MRI scans and decreased temporal lobe perfusion as measured by SPECT scans, while $88 \%$ had decreased frontal lobe perfusion and $61 \%$ had decreased perfusion to other brain areas. Post-treatment HBOT SPECT scans demonstrated that $82.4 \%$ of the patients had an improvement in temporal lobe perfusion, 85.3\% improved in frontal lobe perfusion, and $75.8 \%$ had improvements in perfusion to other brain areas. Behavioral improvements were also observed in these children.

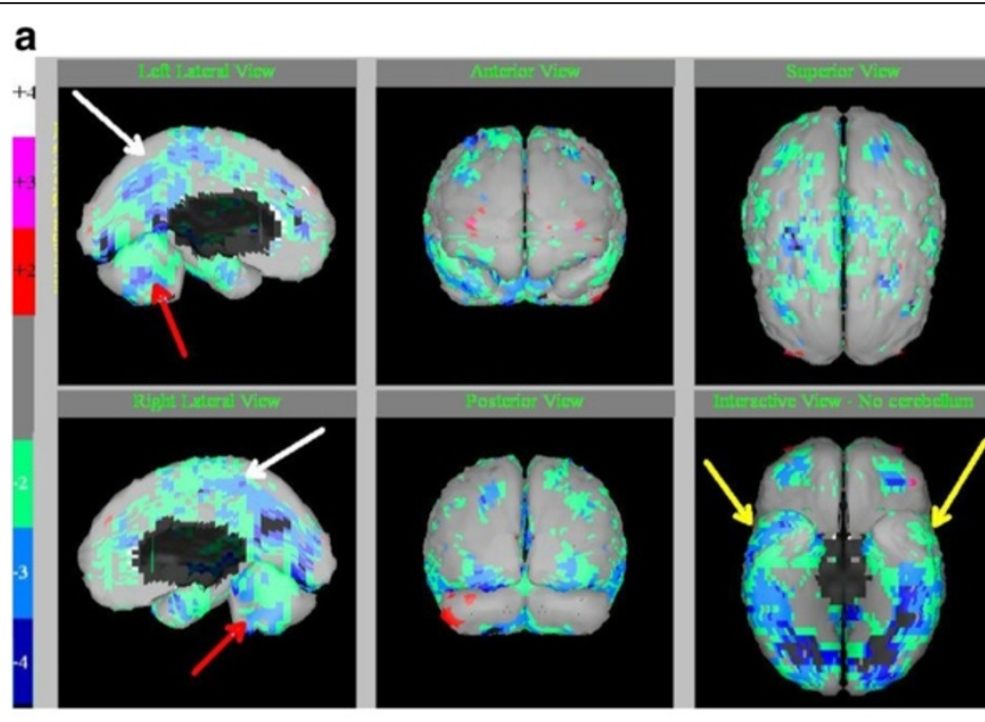

b

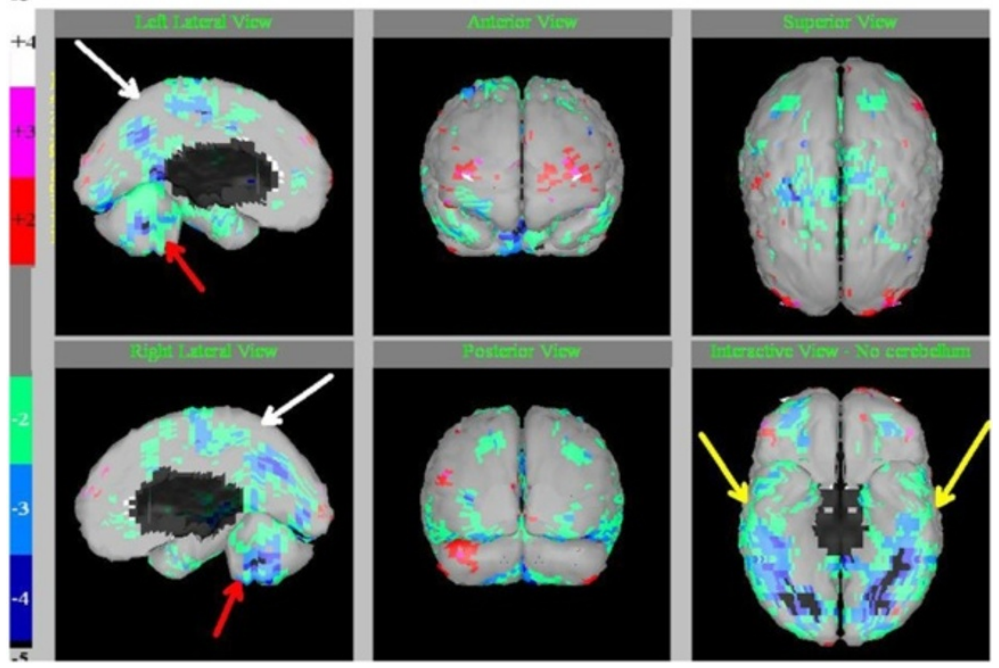

Figure 1 SPECT scan images in a 12 year old boy with autism (a) before and (b) after 80 sessions of HBOT at 1.3 atm. Legend: minus 2 (green) to minus 4 (blue) standard deviations indicate the magnitude of regional hypofunctioning (hypoperfusion). White arrows indicate improvement in deeper cortical hypoperfusion patterns. Red arrows on sagittal slices show the midline cerebellum hypoperfusion and improvements after HBOT. Yellow arrows on the "underside" view show the temporal lobe hypoperfusion with improvements after HBOT. Pictures courtesy of J. Michael Uszler, MD. Credit: Permission for use of figure from Hyperbaric Oxygen for Neurological Disorders granted by Best Publishing Company, Palm Beach Gardens, FL. 
Strengths of this study included objective measurements (SPECT imaging), evaluations by clinicians, and a larger sample size than other studies.

\section{Inflammation in ASD and the effects of $\mathrm{HBOT}$}

Recent studies support the notion that some individuals with ASD manifest neuroinflammation, immune dysregulation and/or gastrointestinal inflammation. A recent review reported that 416 publications implicated inflammation or immune abnormalities in ASD, including 65 publications of neuroinflammation and 31 publications of gastrointestinal inflammation [38]. A number of studies suggest that the gastrointestinal inflammation reported in some children with ASD has characteristics similar to inflammatory bowel disease (IBD) [60-63]. Furthermore, several studies have reported abnormal inflammatory markers in some children with ASD. For example, elevations in TNF-alpha [64-67] and neopterin (a marker of activation of the cellular immune system) [68-70] have been reported in several studies of children with ASD.

Treatment with HBOT has been shown to possess potent anti-inflammatory properties in both animal [71-73] and human studies [74-78]. HBOT has been reported to decrease the production of pro-inflammatory cytokines (including TNF-alpha, interferon-gamma, IL-1 and IL-6) in both animal $[79,80]$ and human studies $[78,81]$ as well as increase counter-inflammatory IL-10 levels [82]. In one study, HBOT also decreased neopterin levels [83]. Furthermore, a recent systematic review reported improvements in studies that used HBOT in IBD [84]. The effect of HBOT on reducing inflammation may be mediated through a pressurerelated effect and not necessarily by the oxygen delivered. For example, one human study reported a reduction in interferon-gamma production by lymphocytes with HBOT at $2.0 \mathrm{~atm} / 10.5 \%$ oxygen but an increase in interferongamma with $100 \%$ oxygen delivered at $1.0 \mathrm{~atm}$ [78].

Two prospective studies have examined the effects of HBOT on biomarkers of inflammation in children with ASD $[85,86]$. In the first study, 12 children received HBOT at $1.3 \mathrm{~atm} / 24 \%$ oxygen and 6 children received $\mathrm{HBOT}$ at $1.5 \mathrm{~atm} / 100 \%$ oxygen. Biomarkers were measured before and after 40 HBOT sessions [85]. C-reactive protein (a general marker of inflammation) dropped in the overall study population $(\mathrm{p}=0.021)$. Children who had the highest $\mathrm{C}$ reactive protein levels showed the largest decrease. Behavioral improvements were also observed in these children.

In the second study, plasma cytokine levels, including some associated with inflammation, were measured before and after 80 HBOT sessions delivered at $1.5 \mathrm{~atm} /$ $100 \%$ oxygen over a 20 week period in 10 children with ASD [86]. Behavioral improvements were observed in these children, but the study reported no significant changes in cytokines during the study. However, the authors noted that none of the children had abnormal cytokine levels at the beginning of the study, making it less likely that a significant change could be observed. Furthermore, since cerebrospinal fluid (CSF) cytokine abnormalities have been reported in some children with ASD $[64,87,88]$, the authors noted that CSF cytokines could have changed. However, CSF cytokines were not measured in the study. Further studies of HBOT in children with ASD who have abnormal cytokines and markers of inflammation are warranted to investigate these findings in more depth.

In addition to these two studies, one of the authors (DAR) has observed a decrease in urinary neopterin levels after HBOT in some children. For example, one child with ASD who was treated with HBOT at $1.5 \mathrm{~atm} /$ $100 \%$ oxygen for 40 treatments over 1 month had a drop in urinary neopterin, measured immediately before starting HBOT and immediately after stopping, from 768 to $391 \mu \mathrm{mol} / \mathrm{mol}$ creatinine, respectively. Another child with ASD who had significant eczema and bowel inflammation with abdominal distension had resolution of eczema, chronic diarrhea and abdominal distension with HBOT at $1.5 \mathrm{~atm} / 100 \%$ oxygen for 40 treatments over 1 month [58]. See Figure 2a-b for pre- and post-HBOT pictures of this child.

\section{Mitochondrial dysfunction in ASD and the effects of $H B O T$}

Some individuals with ASD manifest evidence of mitochondrial dysfunction [34,89]. A recent review article reported that 145 publications implicated mitochondrial dysfunction in ASD [38]. Although treatments for mitochondrial dysfunction remain relatively limited [34], interest has recently increased in using HBOT as a potential treatment. Both animal and human studies have examined the effects of HBOT on mitochondrial function. Several animal models have reported improvements in mitochondrial function with HBOT [90-96]. For example, in one

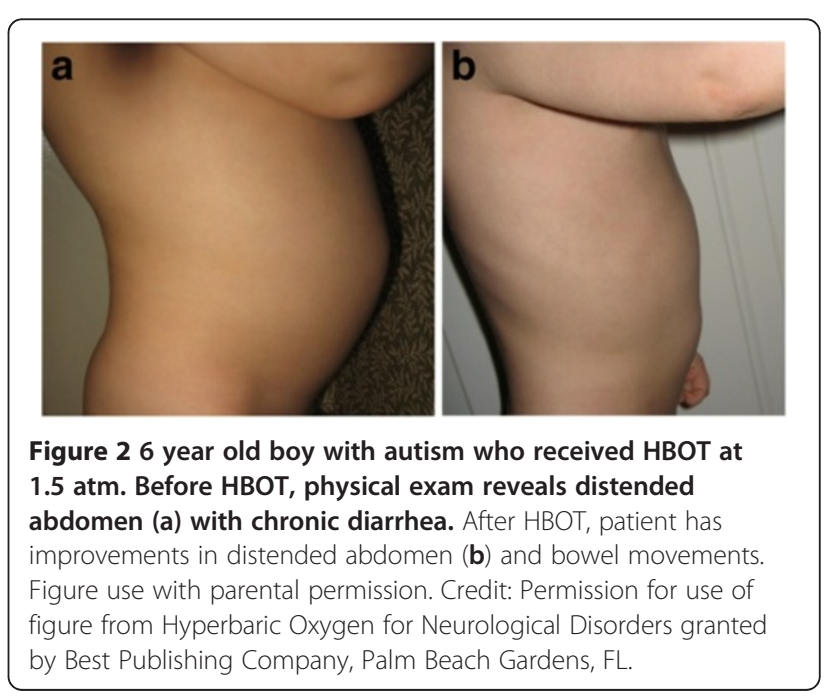


study of rats with normal mitochondrial function, HBOT increased the production of ATP in muscle tissue compared to a control group [97]. A recent study of rat hippocampus reported that HBOT increased mitochondrial biogenesis and autophagy through, in part, an increased production of reactive oxygen species (ROS). Through this process, new healthy mitochondrial were produced and old dysfunctional mitochondrial were destroyed. This study also found increased activation of mitochondrial DNA transcription and replication with HBOT [98]. In a recent controlled study of 69 patients with severe TBI, HBOT at $1.5 \mathrm{~atm} / 100 \%$ oxygen significantly increased brain oxygen levels, increased cerebral blood flow, and decreased CSF lactate levels (high CSF lactate is a marker of mitochondrial dysfunction). In this study, HBOT also improved brain metabolism and mitochondrial function compared with both room air treatment and $100 \%$ oxygen given at normobaric pressure [18]. Although one investigator has reported improvements using HBOT in children with concomitant mitochondrial disease and ASD [99], no clinical studies have been published to date examining the effects of HBOT on mitochondrial function in individuals with ASD; further study in this area is needed.

\section{Oxidative stress in ASD and the effects of $\mathrm{HBOT}$}

Multiple studies have reported evidence of oxidative stress in children with ASD [36,100-102]. A recent review article reported that 115 publications implicated oxidative stress in ASD [38]. Since some children with ASD have evidence of elevated oxidative stress $[38,100]$, some investigators have expressed concern that HBOT could increase oxidative stress in this subset of children [85]. Theoretically, HBOT might increase oxidative stress through the augmented production of ROS from the high concentration of oxygen [103]. This may occur because increased oxygen delivery to mitochondria can increase ROS production. However, HBOT has been shown to upregulate the production of antioxidant enzymes such as superoxide dismutase $[104,105]$, glutathione peroxidase [106], catalase [107], paraoxonase [108] and heme-oxygenase $1[109,110]$. This increase in antioxidant enzyme levels has been termed "conditioning" and can protect against damage caused by ROS [44,111]. Interestingly, increasing ROS may be a potential mechanism of action of HBOT because ROS play an important role in cellular signaling and in triggering certain metabolic pathways [112]. Furthermore, as previously discussed, a slight increase in ROS produced by HBOT may be beneficial as these ROS appear to augment mitochondrial biogenesis [98].

Two studies have reported measurements of oxidative stress markers before and after HBOT in children with ASD $[85,113]$. In the first study, HBOT was administered daily at $1.3 \mathrm{~atm}$ to 48 children with ASD, and superoxide dismutase (SOD), catalase and glutathione peroxidase levels were measured before starting HBOT and after 1 day and 32 days of
HBOT [113]. SOD was 4.5-fold and 4.7-fold higher at 1 and 32 days after starting HBOT, respectively. Mean catalase increased by 1.9-fold after 1 day and after 32 days was 90\% of the initial level before beginning HBOT. Finally, mean glutathione peroxidase increased by 1.4-fold after 1 day and after 32 days was 1.2-fold higher than before beginning HBOT. The effects of HBOT on these antioxidant enzymes may be an example of conditioning as previously discussed.

In the second prospective study, 12 children with ASD received $\mathrm{HBOT}$ at $1.3 \mathrm{~atm} / 24 \%$ oxygen and 6 children received $\mathrm{HBOT}$ at $1.5 \mathrm{~atm} / 100 \%$ oxygen. Biomarkers were measured before and after $40 \mathrm{HBOT}$ sessions [85]. Behavioral improvements were observed in these children and plasma oxidized glutathione levels did not significantly change at $1.3 \mathrm{~atm}(\mathrm{p}=0.557)$ or $1.5 \mathrm{~atm}$ $(p=0.583)$. Since oxidized glutathione is exported from cells when intracellular levels exceed the redox capacity [114], this finding suggests that intracellular oxidative stress did not significantly worsen with $\mathrm{HBOT}$ at these two commonly used lower HBOT pressures in ASD [85].

\section{The effects of HBOT on behavioral measurements in ASD}

The majority of treatment studies using HBOT in children with ASD have measured behavioral rather than physiological parameters. These behavioral studies can be divided into those with and without control children.

\section{Studies lacking control children}

Several case studies have reported behavioral improvements in individuals with ASD from treatment with HBOT. The first published report of the use of HBOT in an individual with ASD was in 1994 [115]. In this report, treatment with HBOT resulted in improvements in mood and social interactions in a three year old child with ASD. The number of treatments and other HBOT parameters were not reported. In 2002, Heuser et al. reported a "striking improvement" in behavior, memory, social interaction, verbalizations and cognitive functioning in a 4 year old boy with ASD after HBOT treatment at $1.3 \mathrm{~atm} / 24 \%$ oxygen for 10 consecutive days [57]. Another investigator observed significant objective improvements in coloring skills (see Figure 3a-d) as well as speech and self-help skills in a 17 year old child with ASD using HBOT at $1.5 \mathrm{~atm} /$ $100 \%$ oxygen for 20 sessions [116]. Burke noted improvements in 2 children with ASD using HBOT at $1.3 \mathrm{~atm} /$ $28 \%$ oxygen, including improvements in communication, aggressiveness and social interaction [117]. Another report noted objective improvements in one child with ASD in handwriting (Figure 4a-b) after 40 treatments with HBOT at $1.3 \mathrm{~atm} / 24 \%$ oxygen, as well as improvements in fine motor skills, bowel function, language and communication [58]. One investigator reported improvements in language, social interaction and overall cognition in a 3 year old boy 
with ASD using HBOT at $1.3 \mathrm{~atm} / 24 \%$ oxygen for 40 treatments. This child also had chronic diarrhea and had the first normal bowel movement in his life with HBOT treatment [99]. In another report, 23 patients with ASD had various improvements in social interaction, language and repetitive behaviors with HBOT at 1.5 atm [47]. Finally, one prospective study of 20 children with ASD reported improvements in communication, social interaction and stereotypical behaviors after 20 HBOT sessions at $1.5 \mathrm{~atm} /$ $100 \%$ oxygen [118].

The first published case-series to examine the effects of HBOT in 6 children with ASD administered HBOT at $1.3 \mathrm{~atm} / 28 \%$ oxygen ( 1 hour treatments for 40 treatments) [119]. Improvements were reported on the Autism Treatment Evaluation Checklist (ATEC), the Childhood Autism Rating Scale (CARS) and the Social Responsiveness Scale
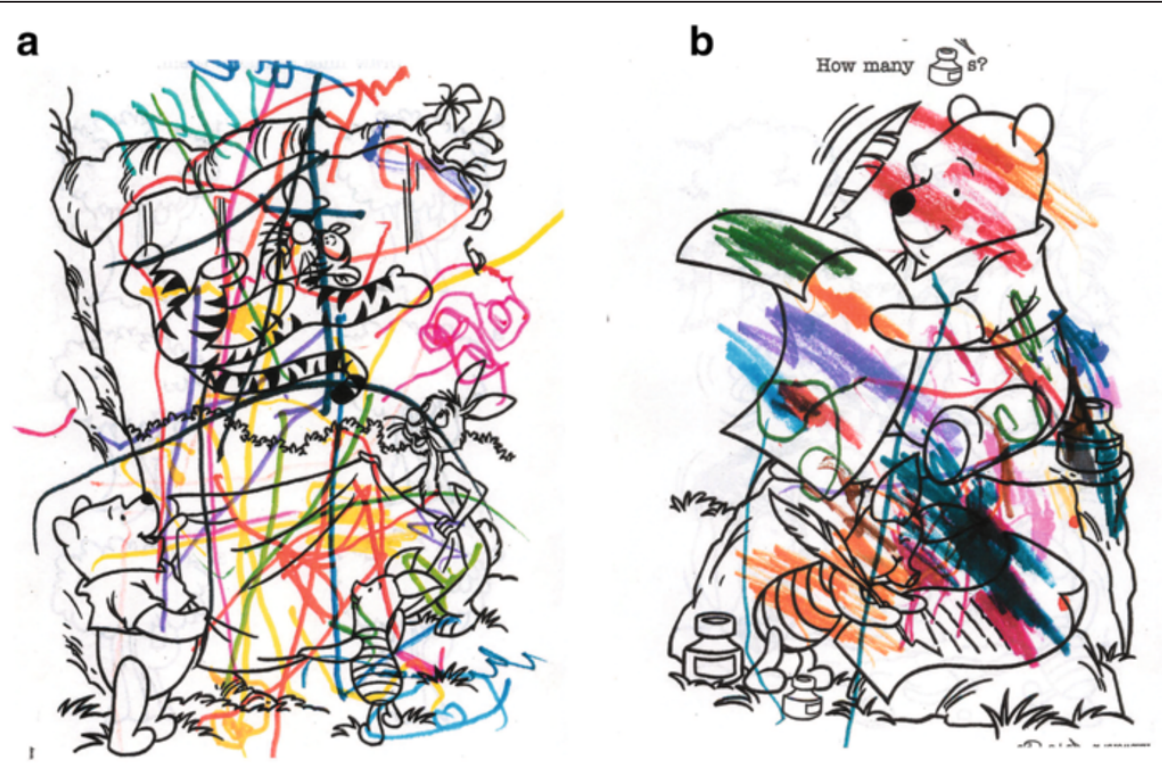

C

d

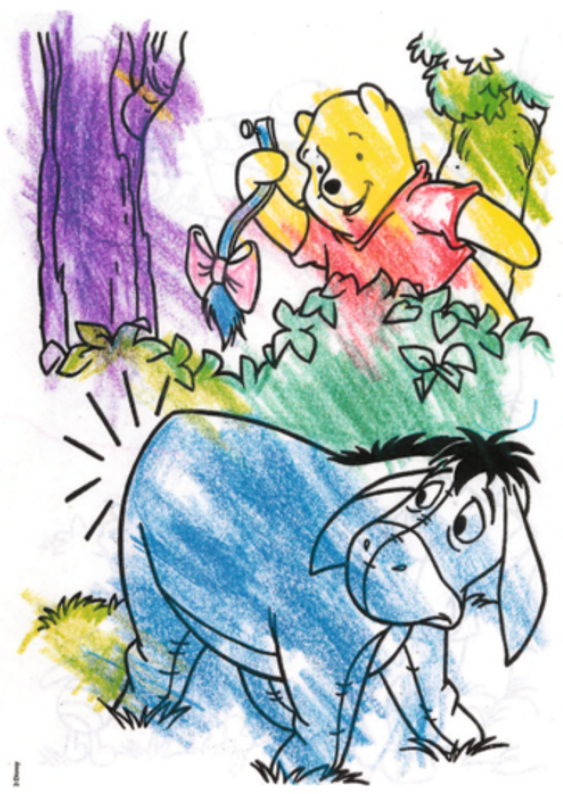

Color the puzzle pieces red. Have a grown-up help you cut them out. Put them together to see what you get. Let your best friend try it, too.
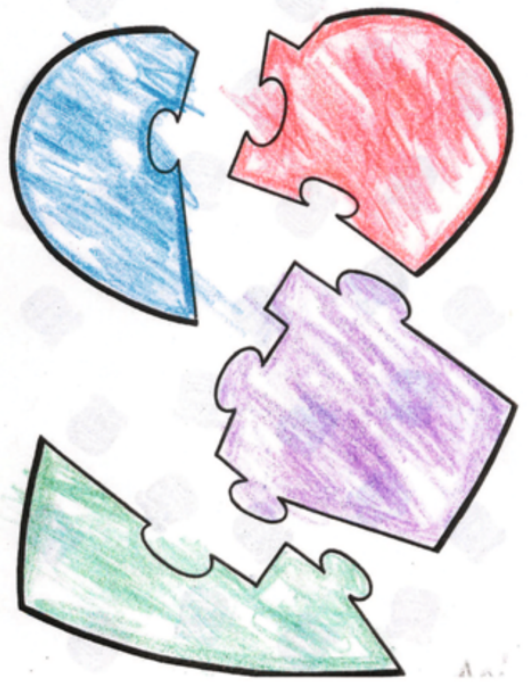

Figure 3 Coloring book pages from 17 year old girl with autism: (a) before beginning HBOT at 1.5 atm/100\% oxygen; (b) after one week of HBOT ( 5 sessions at one hour each), she is beginning to create patches of color to fill in a space; (c) after 3 weeks of HBOT (about 15 hours of HBOT), she uses correct colors for Winnie the Pooh and Eyore, and the foliage except for the tree trunk; and (d) after 5 weeks of HBOT ( 20 hours of HBOT), she begins to respect borders and boundaries and even outlines the inner border with color. After 6 months, her coloring abilities remained stable. Pictures courtesy of Carol L. Henricks, MD. Credit: Permission for use of drawings granted by the Journal of American Physicians and Surgeons. 

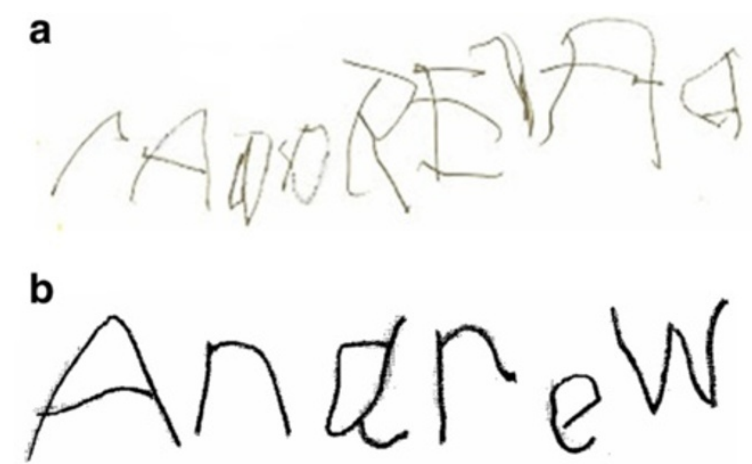

Figure 4 Handwriting in a 6 year old boy (a) before and (b) after $\mathbf{4 0}$ HBOT sessions at $\mathbf{1 . 3} \mathrm{atm}$. Pictures courtesy of James Neubrander, MD. Credit: Permission for use of figure from Hyperbaric Oxygen for Neurological Disorders granted by Best Publishing Company, Palm Beach Gardens, FL.

(SRS). More significant improvements were observed in children under age 5 compared to those older.

A follow-up prospective study examined the effects of HBOT in 18 children with ASD [85]. Twelve children were treated at $1.3 \mathrm{~atm} / 24 \%$ oxygen and 6 were treated at $1.5 \mathrm{~atm} / 100 \%$ oxygen. Hyperbaric sessions were $45 \mathrm{~min}-$ utes in duration for 40 total sessions. As previously noted, markers of oxidative stress and inflammation were measured. Pre- and post-HBOT parent-rated SRS and ATEC indicated significant improvements in each group, including motivation, speech, and cognitive awareness $(\mathrm{p}<0.05$ for each). Strengths of this study included the prospective nature and the use of objective measurements (oxidative stress and inflammatory markers). One group of investigators criticized this study, stating that significant improvements were only observed when both groups (1.3 atm and $1.5 \mathrm{~atm})$ were combined [120]; however, the improvements were indeed significant for each group individually [85].

One small, prospective case series of 3 children with ASD using a multiple baseline design reported no significant improvements (compared to baseline) after 27-40 HBOT treatments at $1.3 \mathrm{~atm} / 88 \%$ oxygen. The treatments were 1 hour in duration, 5 days per week. However, one child had an increase in spontaneous communication and another child had a decrease in problem behaviors with HBOT and an immediate increase in problem behaviors when HBOT was stopped [121]. These improvements were felt by the authors to be unrelated to HBOT but could not necessarily be explained by other factors. Strengths of this study included the prospective nature, the multiple baseline design (including a baseline prior to initiating HBOT), as well as evaluations by therapists and videotaping.

Another prospective study from Thailand reported the effects of HBOT at $1.3 \mathrm{~atm} / 100 \%$ oxygen for 10 sessions (one session per week) in 7 children with ASD [122].
Significant improvements $(\mathrm{p}<0.001$ for each) were observed in social interaction, fine motor and eye-hand coordination, language, gross motor skills and self-help scores. Strengths of this study included the prospective nature and the objective measurements of self-help and motor skills by therapists.

A large, retrospective study from Turkey using HBOT at $1.5 \mathrm{~atm} / 100 \%$ oxygen for 50 sessions at 60 minutes per day reported pre- and post-HBOT ATEC scores [59]. As previously noted, improvements in cerebral perfusion were observed on pre- and post-HBOT SPECT scans. As rated by clinicians/therapists for 54 children with ASD, improvements were observed in speech/language/communication in $79 \%$, sociability in $85.5 \%$, sensory/cognitive awareness in $87 \%$, and health/physical/behavior in $75.2 \%$. Strengths of this study included objective measurements (SPECT imaging), evaluations by clinicians, and a larger sample size than other studies.

One prospective study using a multiple baseline design examined the effects of HBOT at $1.3 \mathrm{~atm} / 24 \%$ oxygen for 40 treatments in 16 children with ASD treated over an average of 56 days [123]. The mean frequency of treatments was 4.78 sessions per week with a range of 2.46 to 7.0 sessions. No consistent positive or negative effects were observed. The authors noted that the study used an observational technique which may not have been sufficient to measure changes in certain areas, such as attention and memory, and that the number of treatments per week was about half as other studies which reported improvements using similar HBOT parameters in children with ASD. Strengths of this study included the multiple baseline design (including a baseline prior to initiating $\mathrm{HBOT}$ ), as well as evaluations by therapists and videotaping.

Finally, a more recent prospective study in 10 children with ASD measured the effects of HBOT at $1.5 \mathrm{~atm} / 100 \%$ oxygen for 1 hour per day, 5 days per week for 80 treatments (completed over 20 weeks, with a 4 week break between the $40^{\text {th }}$ and $41^{\text {st }}$ treatment) on several behavioral scales as rated by parents and clinicians [86]. As previously noted, cytokine markers were measured before and after HBOT. Significant improvements were observed as measured by parent-rated $A B C$ in irritability, lethargy, hyperactivity and overall scores ( $\mathrm{p}=0.02$ or less for each). On the parent-rated PDD Behavior Inventory (PDD-BI), significant improvements were observed in sensory problems, specific fears, and aggressiveness $(\mathrm{p}=0.006$ or less for each). Overall, parents reported improvements in eye contact, imitation, language, tantrums, gastrointestinal problems and eczema. A significant improvement of 2 points (corresponding to "much improved") was observed on the clinician-rated CGI-I scale in all 10 children. Strengths of this study included the prospective nature, evaluations by clinicians, and objective measurements (cytokine levels). 


\section{Studies with control children}

In a recent systematic review published in Medical Gas Research, Ghanizadeh reviewed two randomized, doubleblind, controlled trials using HBOT in children with autism [124]. The first study investigated the effects of HBOT at $1.3 \mathrm{~atm} / 24 \%$ oxygen for 40 treatments, utilizing 2 treatments per day, 5 days per week, over 4 weeks in 33 children with autistic disorder compared to 29 control children with autistic disorder who received slightly pressurized room air (1.03 atm and $21 \%$ oxygen) [125]. Compared to the control group, significant improvements were observed in the treated children on the clinician-rated CGI scale and the parent-rated CGI and ATEC scales in outcomes including overall functioning, receptive language, social interaction, eye contact and sensory/cognitive awareness. Of the children completing more than $1 \mathrm{HBOT}$ session, one child dropped out of the study after nine treatment sessions because asthma symptoms worsened, but this was not felt to be related to the treatment. Ghanizadeh noted that six other children dropped out of the study (four before the study began and two before finishing one full treatment). In this study, six medical centers participated and the findings did not significantly differ across centers. Strengths of this study included evaluations by blinded clinicians and parents (only the HBOT technician was aware of group assignment), an assessment of blinding (which was adequate), an intention-to-treat analysis (children finishing more than 1 HBOT session were included in the analysis), the prospective nature, the use of a control group, and the use of 6 centers (which may have minimized potential biases associated with a single site study).

Several criticisms of this study [125] arose in the comments sections of BMC Pediatrics and by other authors $[120,123]$. One criticism was the claim that the effect of treatment was determined by an intragroup analysis of the treatment group alone, and not by an intergroup analysis of the treatment compared to the control group; however, the analysis was indeed an intergroup analysis where the effects of treatment were compared between the two groups. The authors noted that a typographical error in the manuscript may have contributed to some confusion as \pm SEM (standard error of the mean) was used when all of the reported values were actually \pm SD (standard deviation). Another criticism was that the effect size of the treatment was probably small; however, the effect sizes were calculated as moderate to large (0.55 for the ATEC sensory/cognitive awareness subscale; 1.0 for physician-rated CGI score for overall functioning; and 0.62 for parent-rated CGI score for overall functioning [126]).

In the second controlled study, 18 children with autism were treated with $\mathrm{HBOT}$ at $1.3 \mathrm{~atm} / 24 \%$ oxygen for 80 sessions (completed within 15 weeks) and compared to 16 children treated with placebo (free air-flow through a chamber at ambient pressure). Both groups received intensive ABA therapy and no significant changes were reported using several different behavioral scales [120]. Ghanizadeh [124] noted that twelve participants (26\% of the children entering the study) withdrew from the study. It was not noted if these participants were in the treatment group or the control group or when they dropped out of the study; the scores from these 12 children were not included in the final analyses. Ghanizadeh [124] also observed that the number of patients in each group was small and that both groups showed some improvements during the study. Furthermore, it was noted by Ghanizadeh [124] that since both groups received intensive $\mathrm{ABA}$ therapy during the trial, one explanation for the lack of efficacy observed is that HBOT did not add significant therapeutic effects to intensive ABA. Strengths of this study included the prospective nature, the use of a control group and evaluation by blinded assessors.

Ghanizadeh [124] reported several important distinctions between these two controlled trials $[120,125]$ which might help account for the different outcomes, including the number of participants, potential differences in diagnoses, different age ranges of the study participants, different outcome assessors, possible differences in demographics and autism severity, multicenter [125] vs. single center trial [120], assessment of blinding in one study [125] but not in the second [120], and the intensity of treatments with one study providing a mean of 10 hours of hyperbaric treatments per week [125] and the other study providing, on average, about 5 hours per week [120]. Ghanizadeh also noted that one [120] of the studies had a relatively high dropout rate which may have affected the results of the study. Although the other controlled study had 7 children drop out of the study, 4 dropped before starting the study and two before finishing one treatment session [125]. Moreover, Ghanizadeh noted that for one of the studies [120], there was no assessment of blinding efficacy as described in other HBOT studies $[127,128]$.

\section{Adverse effects of HBOT in ASD}

Most studies did not report any significant adverse events using HBOT in individuals with ASD. Some studies specifically noted there were no adverse events [85,119]. One study reported no adverse effects except for transient tinnitus in one child which resolved within one week [122]. Another study reported several nonserious adverse events, including ear discomfort (4 children), ear infections ( 2 children) and for 1 child each: hyperactivity, increased vocal sensitivity, increased sensory needs, insomnia, fatigue, dehydration, irritability, mouthing of objects, and a seizure [86]. One of the controlled studies reported that one child in the treatment group developed both urinary frequency (urinalysis was 
normal) and a skin rash that the treating physician thought was yeast-related. Another child in the treatment group had worsening of asthma symptoms after nine treatment sessions and was removed from the study; a third child had anxiety and dropped out of the study before finishing one full treatment. In the control group, one child developed abdominal distension and diarrhea during the study and another child had worsening of eczema [125]. The other controlled study reported no adverse events in the treatment group but reported that one of the children in the control group developed hyponatremia and the acute onset of seizures and was removed from the study [120]. In a recent systematic review, Ghanizadeh highlighted that the use of HBOT in children with ASD was associated with minimal adverse events.

\section{Limitations of the reviewed studies}

Many of the reviewed studies suffered from limitations, including the lack of control children, an open-label design, a small number of participants, a retrospective design and the use of parent-rated scales. Indeed, there were only two controlled studies that did not suffer from these types of limitations. These limitations may have contributed to inconsistent findings across studies. In addition, some studies used measurements or observational techniques which may not have been sufficient to measure changes in certain areas, such as attention and memory [123]. The reviewed studies also utilized many different standardized and non-standardized instruments, making it difficult to directly compare the results of studies or to know if there are specific areas of behavior in which HBOT is most effective. None of the studies reported measurements of the long-term effects of HBOT beyond the study period, so it is not known if any of the reported improvements were long lasting.

Most of the reviewed studies relied on changes in behavioral measurements, which may lag behind physiological changes. Based on previous studies of ABA therapy in children with ASD, it is not likely that substantial changes in behavior will be detectable over short observation periods, i.e., less than one year. In fact, studies on ABA therapy report substantial changes over periods from 1 to 4 years [41-43]. Given the complex requirements of brain development, it is likely that the observed physiological and neuroimaging changes observed in children with ASD using HBOT precede developmental and intellectual improvements. In fact, the studies which examined physiological changes with HBOT, especially changes in cerebral perfusion, reported substantial changes which were often observed over short periods of time. Although many of the reviewed studies reported behavioral improvements in some children with ASD, none of the studies lasted more than several months. This time period is probably of insufficient length to quantify the impact of HBOT on development. Additional studies examining the long term effect of HBOT in individuals with ASD are warranted.

Most studies reported improvements with HBOT in physiological abnormalities and/or behavioral outcomes of children with ASD; however, two studies from the same group of researchers did not find any notable improvements [120,123], and a third small study reported minimal improvements [121]. The variability in results between studies could have been due to certain subgroups of children with ASD responding differently to HBOT [123]. For example, it is possible that children with abnormal cytokines, higher inflammatory markers, cerebral hypoperfusion or mitochondrial dysfunction may be more likely to demonstrate improvements. However, many of the behavioral studies did not measure changes in biochemical variables (such as markers of inflammation or oxidative stress). One behavioral study measured changes in cytokine levels, but all of the children treated with HBOT had normal cytokine levels, making it unlikely that a significant change in cytokines would be observed [86]. Additional studies enrolling children with ASD who have certain physiological abnormalities (such as inflammation or cerebral hypoperfusion) and which measure changes in these physiological parameters would be helpful in investigating this further.

Studies which used a higher frequency of HBOT sessions (e.g., 10 sessions per week as opposed to 5 sessions per week) generally reported more significant improvements. This appears to be consistent with studies in other neurological conditions such as traumatic brain injury [17] where studies using a higher mean number of HBOT sessions per month (e.g., 40 treatments within a one month period) generally reported more significant effects. Additional studies are needed to look at various HBOT parameters (pressure and oxygen levels) in children with ASD to help determine optimal treatment parameters.

\section{Conclusions}

HBOT at the pressures commonly used in children with ASD (up to $1.5 \mathrm{~atm} / 100 \%$ oxygen) has been reported to improve cerebral perfusion, decrease markers of inflammation and not worsen oxidative stress markers. Most studies of HBOT in children with ASD reported improvements in several behavioral domains although many of these studies were not controlled. Although the two trials employing a control group reported conflicting results, a recent systematic review noted several important distinctions between these trials. Collectively, the reviewed studies indicate that the use of HBOT in children with ASD is associated with minimal adverse events and is well tolerated. We conclude that HBOT is 
a safe and potentially effective treatment for children with ASD but that further studies are warranted. Future studies would be wise to use standardized behavioral measurement tools and physiological biomarkers in a controlled study design. Targeting ASD subgroups that possess specific physiological abnormalities with HBOT may be a potentially fruitful method for determining which ASD individuals would benefit from treatment with HBOT.

\section{Competing interests}

DAR, CS, SHF, NO, SC, JAB and EAM treat individuals with hyperbaric treatment in their clinical practices and derive revenue from this. KVD works at a hyperbaric center and recommends HBOT, but does not derive revenue from hyperbaric treatments. JJB prescribes hyperbaric treatment but does not derive revenue from this. DAR and EAM have previously received research funding from the International Hyperbarics Association (IHA) for two studies of hyperbaric treatment in children with autism [85,125] and CS previously received research funding from the $\mathrm{HA}$ for one of these studies [125]. JAB has previously received research funding from the IHA for one study of hyperbaric treatment in children with autism and their parents. EAM has received hyperbaric chambers and financial support from OxyHealth LLC for remodeling the Rimland Center, a center for mentoring clinicians interested in learning how to care for children with autism spectrum disorders. DAR and KVD are medical advisors (unpaid) for IHA. REF declares that he has no competing interests.

\section{Authors' contributions}

DR conceived the study and wrote the initial draft. All remaining authors edited the paper for content and suggested changes. All authors read and approved the final manuscript.

\section{Author details}

${ }^{1}$ Rossignol Medical Center, 3800 West Eau Gallie Blvd., Melbourne, FL 32934 USA. ${ }^{2}$ International Child Development Resource Center, 104 Colony Park Dr. Suite 600, Cumming, GA 30040, USA. ${ }^{3}$ Southwest College of Naturopathic Medicine, Department of Pediatrics, Tempe, AZ, USA. ${ }^{4}$ Wisconsin Integrative Hyperbaric Center, 6200 Nesbitt Road, Fitchburg, WI 53719, USA. ${ }^{5}$ Center for Autism Research and Education, 4045 East Union Hills Drive, Suite 116, Phoenix, AZ 85050, USA. ${ }^{6}$ Stockton Family Practice, Stockton Center for Health Care, 56 South Main Street, Suites A \& B, Stockton, NJ 08559, USA. ${ }^{7}$ Center for Autism \& Integrative Health, 3 Hollyhock Lane, Wilton, CT 06897 USA. ${ }^{8}$ Cypress Integrative Medicine, 10562 South Glenstone Place, Baton Rouge, LA 70810, USA. ${ }^{9}$ Pediatric Partners of Ponte Vedra, 5270 Palm Valley Road, Ponte Vedra Beach, FL 32082, USA. ${ }^{10}$ The Rimland Center, 2919 Confederate Ave, Lynchburg, VA 24501, USA. ${ }^{11}$ Department of Pediatrics, Arkansas Children's Hospital Research Institute, University of Arkansas for Medical Sciences, Little Rock, AR 72202, USA.

Received: 29 March 2012 Accepted: 19 May 2012

Published: 15 June 2012

\section{References}

1. Feldmeier JJ, Chairman and Editor: Hyperbaric oxygen 2003: indications and results: the hyperbaric oxygen therapy committee report. Kensington, MD: Undersea and Hyperbaric Medicine Society; 2003.

2. Leach RM, Rees PJ, Wilmshurst P: Hyperbaric oxygen therapy. BMJ 1998 317(7166):1140-1143.

3. Shandling AH, Ellestad MH, Hart GB, Crump R, Marlow D, Van Natta B, Messenger JC, Strauss M, Stavitsky Y: Hyperbaric oxygen and thrombolysis in myocardial infarction: the "HOT MI" pilot study. Am Heart J 1997, 134 (3):544-550.

4. Gill AL, Bell CN: Hyperbaric oxygen: its uses, mechanisms of action and outcomes. OJM 2004, 97(7):385-395.

5. Ackerman NB, Brinkley FB: Oxygen tensions in normal and ischemic tissues during hyperbaric therapy. Studies in rabbits. JAMA 1966, 198 (12):1280-1283.
6. Wang GH, Zhang XG, Jiang ZL, Li X, Peng LL, Li YC, Wang Y: Neuroprotective effects of hyperbaric oxygen treatment on traumatic brain injury in the rat. $J$ Neurotrauma 2010, 27(9):1733-1743.

7. Palzur E, Zaaroor M, Vlodavsky E, Milman F, Soustiel JF: Neuroprotective effect of hyperbaric oxygen therapy in brain injury is mediated by preservation of mitochondrial membrane properties. Brain Res 2008, 1221:126-133.

8. Henninger N, Kuppers-Tiedt L, Sicard KM, Gunther A, Schneider D, Schwab S: Neuroprotective effect of hyperbaric oxygen therapy monitored by MRimaging after embolic stroke in rats. Exp Neurol 2006, 201(2):316-323.

9. Harch PG, Kriedt C, Van Meter KW, Sutherland R: Hyperbaric oxygen therapy improves spatial learning and memory in a rat model of chronic traumatic brain injury. Brain Res 2007, 1174:120-129.

10. Vlodavsky E, Palzur E, Soustiel JF: Hyperbaric oxygen therapy reduces neuroinflammation and expression of matrix metalloproteinase- 9 in the rat model of traumatic brain injury. Neuropathol Appl Neurobiol 2006, 32(1):40-50.

11. Wright JK, Zant E, Groom K, Schlegel RE, Gilliland K: Case report: Treatment of mild traumatic brain injury with hyperbaric oxygen. Undersea Hyperb Med 2009, 36 (6):391-399.

12. Eovaldi B, Zanetti C: Hyperbaric oxygen ameliorates worsening signs and symptoms of post-traumatic stress disorder. Neuropsychiatr Dis Treat 2010, 6:785-789.

13. Lv LQ, Hou LJ, Yu MK, Ding XH, Qi XQ, Lu YC: Hyperbaric oxygen therapy in the management of paroxysmal sympathetic hyperactivity after severe traumatic brain injury: a report of 6 cases. Arch Phys Med Rehabil 2011, 92(9):1515-1518

14. Stoller KP: Hyperbaric oxygen therapy (1.5 ATA) in treating sports related TBI/ CTE: two case reports. Med Gas Res 2011, 1(1):17.

15. Sahni $T$, Jain M, Prasad R, Sogani SK, Singh VP: Use of hyperbaric oxygen in traumatic brain injury: Retrospective analysis of data of 20 patients treated at a tertiary care centre. Br J Neurosurg 2011, 26(2):207.

16. Harch PG, Fogarty EF, Staab PK, Van Meter K: Low pressure hyperbaric oxygen therapy and SPECT brain imaging in the treatment of blastinduced chronic traumatic brain injury (post-concussion syndrome) and post traumatic stress disorder: a case report. Cases J 2009, 2:6538.

17. Harch P, Andrews SR, Fogarty E, Amen DG, Pezzullo JC, Lucarini J, Aubrey C, Taylor DV, Staab P, Van Meter K: A Phase I Study of Low Pressure Hyperbaric Oxygen Therapy for Blast-Induced Post Concussion Syndrome and Post Traumatic Stress Disorder. J Neurotrauma 2012, 29(1):168-185.

18. Rockswold SB, Rockswold GL, Zaun DA, Zhang X, Cerra CE, Bergman TA, Liu J: A prospective, randomized clinical trial to compare the effect of hyperbaric to normobaric hyperoxia on cerebral metabolism, intracranial pressure, and oxygen toxicity in severe traumatic brain injury. J Neurosurg 2010, 112(5):1080-1094

19. Shi XY, Tang ZQ, Xiong B, Bao JX, Sun D, Zhang YQ, Yao Y: Cerebral perfusion SPECT imaging for assessment of the effect of hyperbaric oxygen therapy on patients with postbrain injury neural status. Chin J Traumatol 2003, 6 (6):346-349.

20. Shi $X Y$, Tang ZQ, Sun D, He XJ: Evaluation of hyperbaric oxygen treatment of neuropsychiatric disorders following traumatic brain injury. Chin Med J (Engl) 2006, 119(23):1978-1982.

21. Hardy P, Johnston KM, De Beaumont L, Montgomery DL, Lecomte JM, Soucy JP, Bourbonnais D, Lassonde M: Pilot case study of the therapeutic potential of hyperbaric oxygen therapy on chronic brain injury. J Neurol Sci 2007, 253 (1-2):94-105.

22. Golden ZL, Neubauer R, Golden CJ, Greene L, Marsh J, Mleko A: Improvement in cerebral metabolism in chronic brain injury after hyperbaric oxygen therapy. Int J Neurosci 2002, 112(2):119-131.

23. Golden Z, Golden CJ, Neubauer RA: Improving neuropsychological function after chronic brain injury with hyperbaric oxygen. Disabil Rehabil 2006, 28 (22):1379-1386.

24. Helms A, Evans AW, Chu J, Sahgal A, Ostrowski R, Sosiak T, Wolf G, Gillett J, Whelan $\mathrm{H}$ : Hyperbaric oxygen for neurologic indications-action plan for multicenter trials in: stroke, traumatic brain injury, radiation encephalopathy \& status migrainosus. Undersea Hyperb Med 2011, 38(5):309-319.

25. Stoller KP: Quantification of neurocognitive changes before, during, and after hyperbaric oxygen therapy in a case of fetal alcohol syndrome. Pediatrics 2005, 116(4):586-591.

26. Matchett GA, Martin RD, Zhang JH: Hyperbaric oxygen therapy and cerebral ischemia: neuroprotective mechanisms. Neurol Res 2009, 31 (2):114-121

27. Huang $L$, Obenaus A: Hyperbaric oxygen therapy for traumatic brain injury. Med Gas Res 2011, 1(1):21. 
28. Moss MC, Scholey AB: Oxygen administration enhances memory formation in healthy young adults. Psychopharmacology (Berl) 1996, 124 (3):255-260

29. Scholey AB, Moss MC, Neave N, Wesnes K: Cognitive performance, hyperoxia, and heart rate following oxygen administration in healthy young adults. Physiol Behav 1999, 67(5):783-789.

30. Moss MC, Scholey AB, Wesnes K: Oxygen administration selectively enhances cognitive performance in healthy young adults: a placebocontrolled double-blind crossover study. Psychopharmacology (Berl) 1998 138(1):27-33.

31. APA: Diagnostic and statistical manual of mental disorders. 4th edition. Washington, DC: American Psychiatric Association; 1994.

32. Rice C: Prevalence of autism spectrum disorders - Autism and Developmental Disabilities Monitoring Network, United States, 2006. MMWR Surveill Summ 2009, 58(10):1-20.

33. Schaefer GB, Mendelsohn NJ: Genetics evaluation for the etiologic diagnosis of autism spectrum disorders. Genet Med 2008, 10(1):4-12.

34. Rossignol DA, Frye RE: Mitochondrial dysfunction in autism spectrum disorders: a systematic review and meta-analysis. Mol Psychiatry 2011, 17 (3):290-314

35. Buie T, Campbell DB, Fuchs GJ 3rd, Furuta GT, Levy J, Vandewater J, Whitaker AH, Atkins D, Bauman ML, Beaudet AL: Evaluation, diagnosis, and treatment of gastrointestinal disorders in individuals with ASDs: a consensus report. Pediatrics 2010, 1:S1-18. 125 Suppl.

36. James SJ, Melnyk S, Jernigan S, Cleves MA, Halsted CH, Wong DH, Cutler P, Bock K, Boris M, Bradstreet JJ, et al: Metabolic endophenotype and related genotypes are associated with oxidative stress in children with autism. Am J Med Genet B Neuropsychiatr Genet 2006, 141(8):947-956.

37. Ashwood P, Krakowiak P, Hertz-Picciotto I, Hansen R, Pessah I, Van de Water $\mathrm{J}$ : Elevated plasma cytokines in autism spectrum disorders provide evidence of immune dysfunction and are associated with impaired behavioral outcome. Brain Behav Immun 2010, 25(1):40-45

38. Rossignol DA, Frye RE: A review of research trends in physiological abnormalities in autism spectrum disorders: immune dysregulation, inflammation, oxidative stress, mitochondrial dysfunction and environmental toxicant exposures. Mol Psychiatry 2011, 17(4):389-401.

39. Ming X, Brimacombe M, Chaaban J, Zimmerman-Bier B, Wagner GC: Autism spectrum disorders: concurrent clinical disorders. J Child Neurol 2008, 23 (1):6-13.

40. Herbert MR: Autism: a brain disorder or a disorder that affects the brain. Clinical Neuropsychiatry 2005, 2(6):354-379.

41. Lovaas Ol: Behavioral treatment and normal educational and intellectual functioning in young autistic children. J Consult Clin Psychol 1987, 55(1):3-9.

42. Sallows GO, Graupner TD: Intensive behavioral treatment for children with autism: four-year outcome and predictors. Am J Ment Retard 2005, 110(6):417-438.

43. Eikeseth $\mathrm{S}$, Smith $\mathrm{T}$, Jahr E, Eldevik S: Intensive behavioral treatment at school for 4- to 7-year-old children with autism. A 1-year comparison controlled study. Behav Modif 2002, 26(1):49-68.

44. Rossignol DA: Hyperbaric oxygen therapy might improve certain pathophysiological findings in autism. Med Hypotheses 2007, 68 (6):1208-1227.

45. Buckley JA: How mild hyperbaric oxygen therapy works and why it is good for our children. Medical Veritas 2005, 2:647.

46. Stoller KP, Small T: Interview with Dr. Kenneth P. Stoller: Hyperbaric oxygen therapy (HBOT), Autism, Aspartame and Mercury. Medical, Veritas 2006, 3(1):957-966

47. Harch PG, Small T: Interview with Dr Paul Harch: the application of hyperbaric oxygen therapy in chronic neurological conditions. Medical Veritas 2005, 2(2):637-646.

48. Rossignol DA, Small T: Interview with Dr. Dan A. Rossignol: hyperbaric oxygen therapy improves symptoms in autistic children. Medical Veritas 2006, 3:1-4.

49. Zilbovicius M, Boddaert N, Belin P, Poline JB, Remy P, Mangin JF, Thivard L, Barthelemy C, Samson Y: Temporal lobe dysfunction in childhood autism: a PET study. Positron emission tomography. Am J Psychiatry 2000, 157 (12):1988-1993.

50. Zilbovicius M, Garreau B, Tzourio N, Mazoyer B, Bruck B, Martinot JL, Raynaud C, Samson Y, Syrota A, Lelord G: Regional cerebral blood flow in childhood autism: a SPECT study. Am J Psychiatry 1992, 149(7):924-930.
51. Boddaert N, Zilbovicius M: Functional neuroimaging and childhood autism. Pediatr Radiol 2002, 32(1):1-7.

52. Starkstein SE, Vazquez S, Vrancic D, Nanclares V, Manes F, Piven J, Plebst C: SPECT findings in mentally retarded autistic individuals. J Neuropsychiatry Clin Neurosci 2000, 12(3):370-375

53. Ohnishi T, Matsuda H, Hashimoto T, Kunihiro T, Nishikawa M, Uema T, Sasaki M: Abnormal regional cerebral blood flow in childhood autism. Brain 2000, 123(Pt 9):1838-1844.

54. Critchley HD, Daly EM, Bullmore ET, Williams SC, Van Amelsvoort T, Robertson DM, Rowe A, Phillips M, McAlonan G, Howlin P, et al: The functional neuroanatomy of social behaviour: changes in cerebral blood flow when people with autistic disorder process facial expressions. Brain 2000, 123(Pt 11):2203-2212

55. Wilcox J, Tsuang MT, Ledger E, Algeo J, Schnurr T: Brain perfusion in autism varies with age. Neuropsychobiology 2002, 46(1):13-16.

56. Gendry Meresse I, Zilbovicius M, Boddaert N, Robel L, Philippe A, Sfaello I, Laurier L, Brunelle F, Samson Y, Mouren MC: Autism severity and temporal lobe functional abnormalities. Ann Neurol 2005, 58(3):466-469.

57. Heuser G, Heuser SA, Rodelander D, Aguilera O, Uszler M: In Treatment of neurologically impaired adults and children with "mild" hyperbaric oxygenation (1.3 atm and $24 \%$ oxygen). In Hyperbaric oxygenation for cerebral palsy and the brain-injured child. Edited by Joiner JT. Flagstaff, Arizona: Best Publications; 2002

58. Rossignol DA: The use of hyperbaric oxygen therapy in autism. In Hyperbaric oxygen for neurological disorders. Edited by Zhang JH. Flagstaff, AZ: Best Publishing Company; 2008:209-258.

59. The effects of hyperbaric oxygen therapy in children with autism spectrum disorders: [http://archive.rubicon-foundation.org/xmlui/handle/123456789/ 9163].

60. Ashwood P, Anthony A, Pellicer AA, Torrente F, Walker-Smith JA, Wakefield AJ: Intestinal lymphocyte populations in children with regressive autism: evidence for extensive mucosal immunopathology. J Clin Immunol 2003, 23(6):504-517

61. Balzola F, Barbon V, Repici A, Rizzetto M, Clauser D, Gandione M, Sapino A: Panenteric IBD-like disease in a patient with regressive autism shown for the first time by the wireless capsule enteroscopy: another piece in the jigsaw of this gut-brain syndrome? Am J Gastroenterol 2005, 100(4):979-981.

62. Furlano Rl, Anthony A, Day R, Brown A, McGarvey L, Thomson MA, Davies SE, Berelowitz M, Forbes A, Wakefield AJ, et al: Colonic CD8 and gamma delta T-cell infiltration with epithelial damage in children with autism. J Pediatr 2001, 138(3):366-372.

63. Torrente F, Ashwood P, Day R, Machado N, Furlano RI, Anthony A, Davies SE, Wakefield AJ, Thomson MA, Walker-Smith JA: Small intestinal enteropathy with epithelial IgG and complement deposition in children with regressive autism. Mol Psychiatry 2002, 7(4):375-382. 334

64. Chez MG, Dowling T, Patel PB, Khanna P, Kominsky M: Elevation of tumor necrosis factor-alpha in cerebrospinal fluid of autistic children. Pediatr Neurol 2007, 36(6):361-365.

65. Ashwood P, Anthony A, Torrente F, Wakefield AJ: Spontaneous mucosal lymphocyte cytokine profiles in children with autism and gastrointestinal symptoms: mucosal immune activation and reduced counter regulatory interleukin-10. J Clin Immunol 2004, 24(6):664-673.

66. Li X, Chauhan A, Sheikh AM, Patil S, Chauhan V, Li XM, Ji L, Brown T, Malik $M$ : Elevated immune response in the brain of autistic patients. Neuroimmunol 2009, 207(1-2):111-116.

67. Jyonouchi $\mathrm{H}$, Sun $\mathrm{S}$, Le H: Proinflammatory and regulatory cytokine production associated with innate and adaptive immune responses in children with autism spectrum disorders and developmental regression. J Neuroimmunol 2001, 120(1-2):170-179.

68. Messahel S, Pheasant AE, Pall H, Ahmed-Choudhury J, Sungum-Paliwal RS, Vostanis P: Urinary levels of neopterin and biopterin in autism. Neurosci Lett 1998, 241(1):17-20

69. Sweeten TL, Posey DJ, McDougle CJ: High blood monocyte counts and neopterin levels in children with autistic disorder. Am J Psychiatry 2003, 160(9):1691-1693.

70. Messahel $\mathrm{S}$, Pheasant AE, Pall H, Kerr AM: Abnormalities in urinary pterin levels in Rett syndrome. Eur J Paediatr Neurol 2000, 4(5):211-217.

71. Akin ML, Gulluoglu BM, Uluutku H, Erenoglu C, Elbuken E, Yildirim S, Celenk $\mathrm{T}$ : Hyperbaric oxygen improves healing in experimental rat colitis. Undersea Hyperb Med 2002, 29(4):279-285. 
72. Luongo C, Imperatore F, Cuzzocrea S, Filippelli A, Scafuro MA, Mangoni G, Portolano F, Rossi F: Effects of hyperbaric oxygen exposure on a zymosan-induced shock model. Crit Care Med 1998, 26(12):1972-1976.

73. Sumen G, Cimsit M, Eroglu L: Hyperbaric oxygen treatment reduces carrageenan-induced acute inflammation in rats. Eur J Pharmacol 2001, 431(2):265-268

74. Abbot NC, Beck JS, Carnochan FM, Gibbs JH, Harrison DK, James PB, Lowe JG: Effect of hyperoxia at 1 and 2 ATA on hypoxia and hypercapnia in human skin during experimental inflammation. J Appl Physiol 1994, 77 (2):767-773

75. Takeshima F, Makiyama K, Doi T: Hyperbaric oxygen as adjunct therapy for Crohn's intractable enteric ulcer. Am J Gastroenterol 1999, 94(11):33743375.

76. Nelson EW Jr, Bright DE, Villar LF: Closure of refractory perineal Crohn's lesion. Integration of hyperbaric oxygen into case management. Dig Dis Sci 1990, 35(12):1561-1565

77. Lavy A, Weisz G, Adir Y, Ramon Y, Melamed Y, Eidelman S: Hyperbaric oxygen for perianal Crohn's disease. J Clin Gastroenterol 1994, 19(3): 202-205.

78. Granowitz EV, Skulsky EJ, Benson RM, Wright J, Garb JL, Cohen ER, Smithline EC, Brown RB: Exposure to increased pressure or hyperbaric oxygen suppresses interferon-gamma secretion in whole blood cultures of healthy humans. Undersea Hyperb Med 2002, 29(3):216-225

79. Yang Z, Nandi J, Wang J, Bosco G, Gregory M, Chung C, Xie Y, Yang X, Camporesi EM: Hyperbaric oxygenation ameliorates indomethacininduced enteropathy in rats by modulating TNF-alpha and IL-1beta production. Dig Dis Sci 2006, 51(8):1426-1433.

80. Inamoto Y, Okuno F, Saito K, Tanaka Y, Watanabe K, Morimoto I, Yamashita $U$, Eto S: Effect of hyperbaric oxygenation on macrophage function in mice. Biochem Biophys Res Commun 1991, 179(2):886-891.

81. Weisz G, Lavy A, Adir Y, Melamed Y, Rubin D, Eidelman S, Pollack S: Modification of in vivo and in vitro TNF-alpha, IL-1, and IL- 6 secretion by circulating monocytes during hyperbaric oxygen treatment in patients with perianal Crohn's disease. J Clin Immunol 1997, 17(2):154-159.

82. Buras JA, Holt D, Orlow D, Belikoff B, Pavlides S, Reenstra WR: Hyperbaric oxygen protects from sepsis mortality via an interleukin-10-dependent mechanism. Crit Care Med 2006, 34(10):2624-2629.

83. Altinel O, Demirbas S, Cakir E, Yaman H, Ozerhan $\mathrm{H}$, Duran E, Cayci T, Akgul EO, Ersoz N, Uysal B, et al: Comparison of hyperbaric oxygen and medical ozone therapies in a rat model of experimental distal colitis. Scand J Clin Lab Invest 2011, 71(3):185-192.

84. Rossignol DA: Hyperbaric oxygen treatment for inflammatory bowel disease: a systematic review and analysis. Med Gas Res 2012, 2(1):6

85. Rossignol DA, Rossignol LW, James SJ, Melnyk S, Mumper E: The effects of hyperbaric oxygen therapy on oxidative stress, inflammation, and symptoms in children with autism: an open-label pilot study. BMC Pediatr 2007, 7(1):36

86. Bent S, Bertoglio K, Ashwood P, Nemeth E, Hendren RL: Brief Report: Hyperbaric Oxygen Therapy (HBOT) in Children with Autism Spectrum Disorder: A Clinical Trial. J Autism Dev Disord 2011,

87. Vargas DL, Nascimbene C, Krishnan C, Zimmerman AW, Pardo CA Neuroglial activation and neuroinflammation in the brain of patients with autism. Ann Neurol 2005, 57(1):67-81.

88. Ashwood P, Van de Water J: A review of autism and the immune response. Clin Dev Immunol 2004, 11(2):165-174.

89. Frye RE, Rossignol DA: Mitochondrial dysfunction can connect the diverse medical symptoms associated with autism spectrum disorders. Pediatr Res 2011, 69(5):41-47.

90. Dave KR, Prado R, Busto R, Raval AP, Bradley WG, Torbati D, Perez-Pinzon $M A:$ Hyperbaric oxygen therapy protects against mitochondrial dysfunction and delays onset of motor neuron disease in Wobbler mice. Neuroscience 2003, 120(1):113-120.

91. Boveris A, Chance B: The mitochondrial generation of hydrogen peroxide. General properties and effect of hyperbaric oxygen. Biochem J 1973, 134 (3):707-716

92. Daugherty WP, Levasseur JE, Sun D, Rockswold GL, Bullock MR: Effects of hyperbaric oxygen therapy on cerebral oxygenation and mitochondrial function following moderate lateral fluid-percussion injury in rats. $J$ Neurosurg 2004, 101(3):499-504

93. Gosalvez M, Castillo Olivares J, De Miguel E, Blanco M, Figuera D: Mitochondrial respiration and oxidative phosphorylation during hypothermic hyperbaric hepatic preservation. J Surg Res 1973, 15(5): 313-318.

94. Bar-Sagie D, Mayevsky A, Bartoov B: Effects of hyperbaric oxygenation on spermatozoan motility driven by mitochondrial respiration. J Appl Physiol 1981, 50(3):531-537

95. Lou M, Chen Y, Ding M, Eschenfelder CC, Deuschl G: Involvement of the mitochondrial ATP-sensitive potassium channel in the neuroprotective effect of hyperbaric oxygenation after cerebral ischemia. Brain Res Bull 2006, 69(2):109-116

96. Calvert JW, Zhang JH: Oxygen treatment restores energy status following experimental neonatal hypoxia-ischemia. Pediatr Crit Care Med 2007, 8 (2):165-173

97. Kurt B, Kurt Y, Karslioglu Y, Topal T, Erdamar H, Korkmaz A, Turkozkan N, Yaman H, Odabasi Z, Gunhan O: Effects of hyperbaric oxygen on energy production and xanthine oxidase levels in striated muscle tissue of healthy rats. J Clin Neurosci 2008, 15(4):445-450.

98. Gutsaeva DR, Suliman HB, Carraway MS, Demchenko IT, Piantadosi CA: Oxygen-induced mitochondrial biogenesis in the rat hippocampus. Neuroscience 2006, 137(2):493-504.

99. Van Dyke K: Hyperbaric oxygen therapy (HBOT) for autism: An introduction. Autism File 2009, 33:5-6.

100. Chauhan A, Chauhan V: Oxidative stress in autism. Pathophysiology 2006 13(3):171-181

101. Chauhan A, Chauhan V, Brown WT, Cohen I: Oxidative stress in autism: increased lipid peroxidation and reduced serum levels of ceruloplasmin and transferrin-the antioxidant proteins. Life Sci 2004, 75(21):2539-2549.

102. James SJ, Cutler P, Melnyk S, Jernigan S, Janak L, Gaylor DW, Neubrander JA: Metabolic biomarkers of increased oxidative stress and impaired methylation capacity in children with autism. Am J Clin Nutr 2004, 80 (6):1611-1617

103. Alleva R, Nasole E, Di Donato F, Borghi B, Neuzil J, Tomasetti M: alphaLipoic acid supplementation inhibits oxidative damage, accelerating chronic wound healing in patients undergoing hyperbaric oxygen therapy. Biochem Biophys Res Commun 2005, 333(2):404-410.

104. Ozden TA, Uzun H, Bohloli M, Toklu AS, Paksoy M, Simsek G, Durak H, Issever $H$, Ipek $T$ : The effects of hyperbaric oxygen treatment on oxidant and antioxidants levels during liver regeneration in rats. Tohoku J Exp Med 2004, 203(4):253-265.

105. Gregorevic P, Lynch GS, Williams DA: Hyperbaric oxygen modulates antioxidant enzyme activity in rat skeletal muscles. Eur J Appl Physiol 2001, 86(1):24-27.

106. Gulec B, Yasar M, Yildiz S, Oter S, Akay C, Deveci S, Sen D: Effect of hyperbaric oxygen on experimental acute distal colitis. Physiol Res 2004, 53(5):493-499.

107. Nie H, Xiong L, Lao N, Chen S, Xu N, Zhu Z: Hyperbaric oxygen preconditioning induces tolerance against spinal cord ischemia by upregulation of antioxidant enzymes in rabbits. J Cereb Blood Flow Metab 2006, 26(5):666-674

108. Sharifi M, Fares W, Abdel-Karim I, Koch JM, Sopko J, Adler D: Usefulness of hyperbaric oxygen therapy to inhibit restenosis after percutaneous coronary intervention for acute myocardial infarction or unstable angina pectoris. Am J Cardiol 2004, 93(12):1533-1535.

109. Speit G, Dennog C, Eichhorn U, Rothfuss A, Kaina B: Induction of heme oxygenase- 1 and adaptive protection against the induction of DNA damage after hyperbaric oxygen treatment. Carcinogenesis 2000, 21 (10):1795-1799.

110. Rothfuss A, Radermacher P, Speit G: Involvement of heme oxygenase-1 (HO-1) in the adaptive protection of human lymphocytes after hyperbaric oxygen (HBO) treatment. Carcinogenesis 2001, 22(12):19791985

111. Rothfuss A, Speit G: Investigations on the mechanism of hyperbaric oxygen (HBO)-induced adaptive protection against oxidative stress. Mutat Res 2002, 508(1-2):157-165.

112. Thom SR: Oxidative stress is fundamental to hyperbaric oxygen therapy. J Appl Physiol 2009, 106(3):988-995.

113. Audhya T: Autism Research Institute Garden Grove Think Tank Meeting, 2007. In Adjustment of SOD, GPO \& catalase activity in RBC of normal and autistic children during hyperoxia. Garden Grove, CA:; 2007.

114. Dickinson DA, Forman HJ: Glutathione in defense and signaling: lessons from a small thiol. Ann N Y Acad Sci 2002, 973:488-504.

115. Anonymous: Little Michael's development had stopped--It was called "childhood autism" until hyperbaric oxygen therapy!. Hyperbaric Oxygen Report 1994, 1(1):1-3. 
116. Henricks CL: Ani's story: A case study in late improvement in neurologic function after hyperbaric oxygenation therapy. I Amer Physicians Surg 2010, 15(3):94-95.

117. Burke C: Hyperbaric Oxygen Therapy. Supertwins Magazine 2007, 17(2):1-2.

118. Treating children with autism using hyperbaric oxygen therapy: [http://www. hyperbaricmedicinecenter.com/images/pdf/autism_study.pdf].

119. Rossignol DA, Rossignol LW: Hyperbaric oxygen therapy may improve symptoms in autistic children. Med Hypotheses 2006, 67(2):216-228.

120. Granpeesheh D, Tarbox J, Dixon DR, Wilke AE, Allen MS, Bradstreet JJ: Randomized trial of hyperbaric oxygen therapy for children with autism. Research Autism Spectrum Disorders 2010, 4:268-275.

121. Lerman DC, Sansbury T, Hovanetz A, Wolever E, Garcia A, O'Brien E, Adedipe $\mathrm{H}$ : Using behavior analysis to examine the outcomes of unproven therapies: An evaluation of hyperbaric oxygen therapy for children with autism. Behavior Analysis in Practice 2009, 1(2):50-58.

122. Chungpaibulpatana J, Sumpatanarax T, Thadakul N, Chantharatreerat C, Konkaew M, Aroonlimsawas M: Hyperbaric oxygen therapy in Thai autistic children. J Med Assoc Thai 2008, 91(8):1232-1238.

123. Jepson B, Granpeesheh D, Tarbox J, Olive ML, Stott C, Braud S, Yoo JH, Wakefield A, Allen MS: Controlled Evaluation of the Effects of Hyperbaric Oxygen Therapy on the Behavior of 16 Children with Autism Spectrum Disorders. J Autism Dev Disord 2011, 41(5):575-588.

124. Ghanizadeh A: Hyperbaric oxygen therapy for treatment of children with autism, a systematic review of randomized trials. Med Gas Res 2012, 2 (1):13.

125. Rossignol DA, Rossignol LW, Smith S, Schneider C, Logerquist S, Usman A, Neubrander J, Madren EM, Hintz G, Grushkin B, et al: Hyperbaric treatment for children with autism: a multicenter, randomized, double-blind, controlled trial. BMC Pediatr 2009, 9:21.

126. Cohen J: Statistical power analysis for the behavioral sciences (second edition). Hillsdale, NJ: Lawrence Erlbaum Associates; 1988.

127. Clarke D: Effective patient blinding during hyperbaric trials. Undersea Hyperb Med 2009, 36(1):13-17.

128. Clarke RE, Tenorio LM, Hussey JR, Toklu AS, Cone DL, Hinojosa JG, Desai SP, Dominguez Parra L, Rodrigues SD, Long RJ, et al: Hyperbaric oxygen treatment of chronic refractory radiation proctitis: a randomized and controlled double-blind crossover trial with long-term follow-up. Int $J$ Radiat Oncol Biol Phys 2008, 72(1):134-143.

doi:10.1186/2045-9912-2-16

Cite this article as: Rossignol et al:: Hyperbaric oxygen treatment in autism spectrum disorders. Medical Gas Research 2012 2:16.

\section{Submit your next manuscript to BioMed Central and take full advantage of:}

- Convenient online submission

- Thorough peer review

- No space constraints or color figure charges

- Immediate publication on acceptance

- Inclusion in PubMed, CAS, Scopus and Google Scholar

- Research which is freely available for redistribution 